\title{
Políticas públicas e infancia: deseos y límites a la igualdad en la educación*
}

\author{
MARIANO NARODOWSKI \\ Universidad Torcuato Di Tella
}

\section{IMAGINEMOS EL SIGUIENTE ESCENARIO:}

Finalmente, el Estado se hizo cargo del control sobre la educación escolar. Con anterioridad existían escuelas controladas autónomamente por educadores y por corporaciones religiosas con una regulación estatal inexistente o mínima. Pero desde las décadas finales del siglo XIX los diferentes Estados nacionales adquieren progresivamente los recursos políticos y económicos para gobernar por su cuenta a las crecientes masas de niños y de hacerlo en instituciones escolares (Archer, 1979). ${ }^{1}$

En función de una nueva construcción social y de una nueva disposición económica, la mayoría de los Estados proclaman la gratuidad universal de la asistencia escolar, sobre todo de la denominada educación primaria, básica o fundamental. Esto implicó que se abolieron los aranceles para el acceso a la educación; que los edificios escolares y los útiles para aprender comenzarían a ser financiados por el erario público; y, talvez más importante, los docentes, que antes subsistían merced a lo que podían cobrar por enseñar y que sólo dependían de sí mismos o de la corporación religiosa a la que pertenecían, pasan a ser asalariados

\footnotetext{
* Trabajo solicitado para ser expuesto en la 35a Reunião Anual da Associação Nacional de Pós-Graduação e Pesquisa em Educação (ANPEd), Porto de Galinhas, Brasil, 2012.

1 El proceso que aquí se inicia fue antecedido por un largo y complejo proceso de estatalización de la educación en el sentido foucaultiano, que ya hemos analizado en trabajos previos. Véase: Narodowski (2001), Narodowski y Brailovsky (2005).
} 
del Estado que los contrata, su nuevo status es el de empleados o servidores públicos (Archer, 1979). ${ }^{2}$

Durante los primeros años del siglo XX, la consigna se dejó escuchar en los países occidentales y un poco más tarde en el resto del mundo, propagada incluso por agencias internacionales dedicadas a este menester: de ahora en adelante, todas las familias deberán enviar a sus hijos a escuelas -"Dejad que los niños vengan a mi” (Martinez Boom, 2011).

Pero se trata ahora de escuelas financiadas por el Estado y la educación que habrán de recibir estará principalmente brindada por maestros formados por el Estado, habilitados por el Estado, pagos por el Estado y que impartirán unos conocimientos regulados por el Estado tanto en su contenido como en su metodología. A esta escuela habrá de denominársela "escuela para todos", o más frecuentemente "escuela común".

¿Por qué el Estado ahora puede hacerse cargo de la educación escolar? ¿Cuál es la fuerza que permite en este tiempo de cambios el surgimiento de esta nueva forma de control sobre la población, especialmente sobre la población infantil? Podríamos ensayar varias respuestas resumiendo las numerosas hipótesis que al respecto fueron formulándose en el último siglo. ${ }^{3}$ Una primera, de carácter más bien ideológico, explica que la población acepta esta nueva situación con buenos ojos incluso como respuesta a sus peticiones y hasta como conquista efectuada por medio de luchas sociales. Se valoraba a la educación escolar no solamente en términos de bien público, en la medida que una población mejor educada contribuirá a una mejor democracia y proveerá de mejores recursos humanos para el desarrollo económico, sino también en términos de bien privado, dado que la obligación de las familias a escolarizar a sus hijos fue acompañada de la creencia generalizada de que mejorar su educación supone mejorar, al menos intergeneracionalmente, el estándar de vida familiar y, con suerte, su eventual inserción en la pirámide social. Es verdad que puede haber existido resistencia entre quienes educaban a sus hijos de una manera o con un contenido que se ha tornado del todo incompatible con el nuevo rol estatal, pero fueron apenas escaramuzas menores si se las analiza a la luz de la perspectiva histórica: en este escenario, el Estado ha logrado una fuerte legitimidad ideológica la que acompaña su capacidad de sostenimiento financiero en torno a la escuela (Archer, 1979).

Ese conjunto de creencias en los beneficios de la educación que las sociedades del siglo XX construyeron vertiginosamente estaba sostenido en aquel complejo de legitimidad ideológica representado por el discurso de una democracia que abrevaba,

2 Los procesos de incorporación de la fuerza laboral docente al aparato estatal son enteramente territoriales y deben ser considerados para cada caso. Un enfoque para los Estados Unidos puede verse en Eisenmann (1991); para el caso colombiano véase Martinez Boom y Castro (1991), entre numerosos estudios nacionales o sub-nacionales.

3 Para una explicación de la necesidad de que el Estado intervenga activamente, por medio de políticas públicas, en el sector educativo, remitimos al ya clásico libro de Rawls (1993). 
en lo pedagógico, en el pensamiento del siglo XVII y el ideal pansófico formulado por Comenius y que sostenía que debía enseñarse todo a todos (Narodowski, 2001). John Dewey, en Democracy and education, le dio una forma modernizada a estos viejos postulados (Dewey, 1916/2008).

Ya sea que el Estado se haya proclama democrático (en su versión tradicional definido rápidamente como "del pueblo, para el pueblo y por el pueblo") y por lo tanto se posiciona en contra de cualquier forma corporativa o parcial de representación social o política y se define como representando el interés general de la sociedad o sea en algunas de las modalidades en las que el Estado se definía por la representación de un sector o clase; en cualquiera de su variantes durante el siglo XX, la consecuencia en el campo de la provisión de educación escolar (como de muchos otros bienes sociales que el Estado distribuye) se construyó como en ningún otro momento en la historia de la humanidad el principio de igualdad: al menos en la proclama, nadie tiene privilegios sobre los otros en virtud de la ostentación de ninguna clase de argumento para obtener más y/o mejores experiencias o prácticas escolares. En este escenario, la igualdad se torna un principio irrenunciable ya que su trasgresión cuestiona la legitimidad originaria de la actuación de Estado como proveedor de bienes educacionales. ${ }^{4}$

La aplicación de este principio no es neutral: el Estado dispone de respuestas políticas y legales que suponen mecanismos coercitivos que convalidan su control sobre la educación escolar y efectivizan la fijación de los cuerpos de los niños entre los muros de los establecimientos escolares. Una de ellas es la sanción de normativas que estipulan la universal obligatoriedad de la educación escolar. Para esto se define una franja etaria (por ejemplo, todos los niños entre 6 y 14 años) y determinados niveles de escolaridad (usualmente primario o fundamental aunque esto pudo haberse extendido) y determina que todos los individuos que pertenecen a ese conjunto no pueden dejar de asistir a la escuela (Tyack, 1976).

Si bien durante todo el siglo XX la obligatoriedad escolar fue ora un dato presentado como "natural" por parte de las sociedades que se mostraban más avanzadas, ora una proclama política de los sectores sociales partidarios de la distribución generalizada de la educación escolar, el proceso de fijación de la infancia en el interior de escuelas llevó un largo tiempo y no desdeñó recursos para alcanzarlo llegando, incluso, a la utilización de la fuerza policial para conseguir este cometido. ${ }^{5}$

La obligatoriedad escolar definida por el Estado trae consigo la construcción de un determinado criterio de educabilidad infantil; es decir, una definición de quiénes y en qué condiciones son educables pero en el escenario de un Estado democrático,

4 El concepto de igualdad que estará implícitamente presente en el desarrollo de este artículo es aún "pre distributivo"; o sea, una ontología anterior a toda forma igualitaria de distribución social de bienes (Miller, 2000).

5 Como diferentes investigaciones lo reflejan para los respectivos espacios nacionales, la policía no dejó de jugar un papel central en la incorporación de ingentes masas infantiles a las escuelas. Véase, por ejemplo, Martinez Boom (2005). 
la educabilidad es ex ante universal y en virtud del principio de igualdad no deben existir limitaciones a la escolaridad basadas en criterios sociales, políticos, ideológicos, religiosos, de género o étnicos.

Este escenario presupone que todos los seres humanos poseen un bagaje genético equivalente y por lo tanto similares capacidades inscriptas en su potencial de partida: no hay diferencias significativas entre hombres y mujeres, razas, condiciones sociales de nacimiento o cualquier otra diferenciación por el estilo. Sin embargo, la delimitación precisa de la educabilidad predispuso a la existencia de algunas restricciones socialmente aceptables y por ende no concebidas como acciones discriminatorias sino más bien como prácticas naturales de la organización de lo escolar.

Una de ellas es la propia delimitación etaria: el Estado, por medio de su burocracia y amparada discursivamente en los avances de la pediatría, la psicología del niño y la pedagogía, define cuándo es el momento adecuado para que los individuos sean obligados a educarse en escuelas, asignando, además, ciertos lugares escolares en función de la edad. La matriz originaria de esta delimitación esta en los viejos textos pedagógicos del siglo XVII pero, con el tiempo, las disciplinas dedicadas al estudio de la infancia hicieron más sofisticada la mirada sobre el tema.

En efecto, en la Didactica magna, Comenius (1986) separa en cuatro las "edades de la vida" e incluye a cada una de ellas en un momento de la escolarización: hasta los 6 años en la escuela materna, hasta los 12 en la elemental, hasta los 18 en el gimnasio y hasta los 24 en la academia. Si bien con el tiempo la psicología del niño y la pedagogía refinaron algunas de estas categorizaciones, casi todos los sistemas educativos estatales han confirmado la intuición comeniana y la han mantenido a lo largo de los siglos.

Otra delimitación supuestamente natural consecuente con criterios de educabilidad presente en nuestro escenario consistió en la identificación de aquellos niños que por motivos igualmente naturales no pueden ser educados en escuelas. Tanto el criterio de educabilidad como el procedimiento de su identificación y posterior discriminación también en este caso corresponden a la burocracia estatal en consonancia con avances científicos, pero en este tipo de situaciones, y a diferencia de la permanencia notable en el tiempo de la delimitación etaria, la determinación de los niños no-educables en escuelas suele variar continuamente $y$, en nuestro escenario, los estados democráticos obligan a que estos individuos se eduquen pero en escuelas especiales en lugar de escuelas comunes.

Con el tiempo, muchas de las exclusiones escolares basadas en la capacidad intelectual o emocional de los niños fueron denunciadas por las pedagogías críticas como encubridoras de verdaderas exclusiones basadas en cuestiones de género, etnia o clase social. En esta línea, a lo largo del tiempo fueron cayendo diferentes estereotipos: de género como la creencia de que las mujeres eran menos competentes que los hombres para resolver problemas que requirieran altas dosis de abstracción, estereotipos raciales o étnicos, como el que postulaba que los negros sólo podían acceder a unos pocos conocimientos básicos, ya que su principal destreza era la 
fuerza física, o de clase social, como los estereotipos que postulaban que los hijos de obreros sólo podían recibir educación vinculada al trabajo manual ya que otro tipo de saberes iría en detrimento de sus genuinas aspiraciones culturales. ${ }^{6}$

El discurso de la pedagogía crítica, pues, llegó para quedarse y gracias en gran medida a su contribución, una a una fueron cediendo las resistencias formales e incluso implícitas a educar a un todos generalizado e irrestricto. El "derecho a la educación” pasó a ser universalizado como un derecho inalienable de la infancia y ya nadie osa cuestionar públicamente la pertinencia de un criterio de educabilidad extendido al máximo. Obviamente, las lógicas de la exclusión de la infancia en la escuela fundamental se han hecho más sutiles, prácticamente invisibles pero en rigor de verdad no resisten ni por un momento su desenmascaramiento ni la denuncia pública: ya nadie predica, como antaño, que alguien merezca o necesite menos o peor educación que ningún otro. ${ }^{7}$

Tanto la obligatoriedad expresada legalmente a la concurrencia a la escuela como la compulsión práctica mediante el uso estatal de la violencia y la generalización de los beneficios de la educabilidad expresan la existencia de otro principio fundamental en este escenario: el interés por la infancia apenas parcialmente representado por sus respectivos progenitores: la infancia es también, y sobre todo, razón de Estado. El estatuto legal de la infancia en la cultura occidental -en nuestro escenario- no está limitado solamente a las decisiones privadas de sus padres respecto de su futuro -la denominada patria potestad- sino que estas decisiones, cuando están vinculadas a aspectos significativos de su crianza y educación deben, como mínimo, ser confirmadas por el Estado. ${ }^{8}$

La obligatoriedad escolar no solamente que no permite que los niños sean educados únicamente por sus propios padres sino que además restringe las actividades productivas o laborales a cargo de niños en situación de ser escolarizados. En este sentido la escuela es, además, un poderoso regulador de la vida de las personas respecto de su ingreso en el mercado laboral y por ende del coste de la fuerza de trabajo. La escuela en tanto razón de Estado resulta en este escenario un recurso de contralor biopolítico de ingentes masas poblacionales. ${ }^{9}$

El respaldo financiero estatal a la obligatoriedad es, en este escenario, un mecanismo fundamental para su cumplimiento y también para el respeto al denominado

6 Resulta materialmente imposible reseñar en una nota al pie los aportes de la pedagogía crítica denunciando estereotipos de género, clase, raza etc. Podríamos afirmar que estas objeciones, paradójicamente, forman parte del mainstream de nuestro escenario y que lo crítico ya se convirtió en el canon.

7 El caso paradigmático está representado por la obra de John Locke (1971).

8 La posibilidad que brinda la modernidad de que la infancia pueda ser asumida como potestad adulta se corresponde con el desarrollo de una derivación del concepto kantiano de "minoría de edad" que por motivos de espacio no habremos de desarrollar en el presente trabajo. Un acercamiento podrá hallarse en Narodowski (2011).

9 Sobre el valor económico de la infancia -y del trabajo infantil- véase el clásico trabajo de Zelizer (1994). 
"principio de igualdad". La escuela obligatoria para los niños suele ser gratuita: es decir, financiada por el Estado sin que medie pago alguno de matrícula para su inscripción. Otro mecanismo diferente y complementario es la utilización de incentivos positivos a la concurrencia de los niños a la escuela: comida, vestimenta, e incluso dinero en efectivo suelen ser contraprestaciones que el Estado ofrece a las familias. Por último, además de la gratuidad escolar el Estado puede solventar los gastos decurrentes de la actividad escolar en forma total o parcial: uniformes, útiles, textos e incluso transporte. En alguna medida, el hecho de que el Estado financie la educación obligatoria compensa el costo que para las familias tiene la oportunidad educacional de sus hijos al no poder contar con ellos para otras tareas que hacen a la subsistencia.

Si la escuela fundamental no fuese gratuita y, por tanto, cada familia debiera costear la escolarización de sus propios hijos, peligraría la posibilidad misma de la escuela común y además no existiría igualdad, ya que los recursos de los sectores sociales más empobrecidos de la población jamás se equipararían a la cantidad y calidad de los recursos que pueden costear los sectores de mayor poder de compra.

Como ya ha podido verse, en el escenario que estamos describiendo existen clases sociales que se distinguen entre sí tanto por el lugar que ocupan en el proceso de producción de bienes como en el nivel de ingresos que percibe cada hogar: desde el punto de vista económico se trata de una sociedad de desiguales, por lo que si se replicara este tipo de relación social también en el sistema educativo, se conformaría un mercado en el que algunos podrán acceder a bienes sociales vinculados a la escuela al que otros no tendrían acceso o conseguirían, apenas, un acceso parcial.

Por eso, el financiamiento estatal generalizado parece ser la única opción capaz de igualar el terreno de juego de forma tal que todos reciban la misma educación. La escuela común propone igualar educacionalmente a los que son desiguales económicamente y de eso hace, en este escenario, su principal bandera democratizante. ${ }^{10}$

El financiamiento estatal de la educación escolar de los niños va a estar dado por la distribución de los recursos del Estado, los que a su vez fueron recaudados -en este escenario- en función de algún principio de proporcionalidad respecto del nivel de ingresos de cada hogar y a la renta de cada empresa. Esos impuestos recaudados suelen ser inespecíficos y sirven también para que el Estado financie otras actividades (la salud pública, la infraestructura, la defensa nacional etc.) y son recaudados centralizadamente, aunque pueden existir diferentes unidades centralizadas de recaudación: federal/nacional; sub-nacional: provincias, municipios, distritos etc.

$\mathrm{El}$ resultado de este procedimiento es, en este escenario, completamente favorable para los sectores sociales de menores recursos ya que si bien en términos relativos es posible que las familias de menores ingresos paguen en concepto de impuestos una parte proporcionalmente mayor del total en comparación con las

10 Para un debate más profundo sobre la teoría y la historia de la escuela común puede verse Tyack (2003), o la visión más crítica al concepto (Glenn, 1988). 
familias de mayores recursos, la totalidad de lo recaudado estará compuesto en un monto mayor, en términos absolutos, por aquello tributado por los hogares y las empresas de mayores recursos. La igualdad educativa necesita de redistribución social de recursos.

Este motivo es muy importante para que todos los sectores sociales, en este escenario, hayan finalmente aceptado de muy buen grado enviar a sus hijos a escuelas gratuitas. ${ }^{11}$ Los de mayores recursos, porque una vez que fueron compelidos a pagar impuestos pueden usar un servicio provisto por el Estado al que ellos contribuyen en mucho a financiar; las de menores recursos, porque pueden gozar de escuelas con un nivel de financiamiento superior al que tendrían si cada familia pagara su propia educación, como en el pasado anterior a la escuela común financiada por el Estado. En la retórica de los sistemas educativos construidos desde finales del siglo XIX; en este escenario, los hijos de los pobres tienen el derecho a ser educados como si fueren hijos de no pobres: como iguales.

Evidentemente, así se consolida el derecho a la educación que está refrendado por el corpus legal de toda sociedad que se pretenda democrática (Wilkins, 2005). La realización plena de este derecho de la infancia habrá de garantizar chances igualadoras a las clases sociales menos agraciadas que si el mismo no existiera (o si el Estado no lo garantizara debidamente). Por supuesto, las posibilidades de igualación efectiva por medio de la educación escolar suponen una empresa más ambiciosa y, en este escenario, solamente sería posible en el contexto de la ilimitada reproducción intergeneracional de la educación escolar común tanto de los pobres como de los no pobres. Además, este objetivo debería ser también intergeneracionalmente refrendado, por una creciente redistribución social. ${ }^{12}$

\section{ESCUELAS PARA LA IGUALDAD}

En este escenario, en la medida que el Estado respeta al principio de igualdad, la oferta de escuelas debe cumplir dos requisitos iniciales: debe ser de cobertura universal -es decir, nadie puede quedarse sin una vacante para educarse- $y$, además, todas las familias deben tener, no muy lejos de su hogar, una escuela a la que enviar a sus hijos -grandes distancias aumentan los costos de oportunidad producto de la necesidad de transporte y cuestionan el principio de igualdad de oportunidades. Subsidiariamente, el Estado podría financiar el transporte de aquellos que no tienen una escuela cerca pero se trataría de un second best (segundo mejor) porque

11 Por supuesto que la historia de la escolarización no estuvo exenta de resistencias diversas por parte de los sectores más empobrecidos a entregar a los hijos a una institución estatal. En Narodowski (2001) hemos desarrollado algunas posiciones al respecto.

12 En este escenario, el mecanismo que habrá de garantizar una redistribución con consistencia intergeneracional es la acumulativa limitación del derecho a la herencia y el aumento progresivo en el impuesto respectivo (Hincapié; Barriga Dávalos, 2011). 
la distancia podría generar desventajas comparativas que atentan contra la igualdad (Levin, 1991).

Ahora bien, es absolutamente fundamental a este escenario que no haya diferencias significativas entre la oferta pedagógica de una escuela y la de otra: las escuelas deben proveer una práctica educacional homogénea en todos sus aspectos y por este motivo es que conviene enviar a los hijos, por motivos de comodidad, a la escuela más cercana al hogar: no habrá de ser posible hallar características o valores diferenciales entre establecimientos; todas las escuelas deben funcionar como si fueran sólo una. ${ }^{13}$

Para que esta homogeneidad completa suceda, la burocracia estatal juega un rol central en el proceso de planificación de la oferta escolar como así también en el proceso de su control o inspección. Desde el punto de vista demográfico, por ejemplo, en este escenario la burocracia estatal planifica la apertura de escuelas en función de la demanda cuantitativa de la población a fin de que ningún niño educable quede fuera de la escolarización y haya vacantes para todos ellos. Para eso edifica escuelas de acuerdo a la concentración demográfica y está permanentemente atenta a la supervisión de los cambios poblacionales para así acompañarlos con la construcción de nuevas escuelas.

Los edificios escolares que construye el Estado, en este escenario, deben ser semejantes unos a otros; es decir, precisan contar con la misma estructura arquitectónica y las mismas comodidades, pudiendo existir pequeñas diferencias relativas al terreno en el que se construye, a la densidad demográfica (mayor densidad requerirá escuelas más grandes) y a elementales normas de adecuación climática; pero ninguna escuela debe ofrecer características por sobre otras.

Este paisaje escolar homogéneo precisa de una burocracia estatal que planifica, administra y controla la provisión de educación escolar: sin ella, la lógica de una sociedad desigual habrá de generar una oferta correspondientemente heterogénea. Esta burocracia estatal que gobierna la educación posee una forma piramidal en la que en la ancha base se encuentran las escuelas en tanto unidades homogéneas que replican las decisiones tomadas en los niveles superiores: un Ministerio de Educación o similar que organiza el funcionamiento de la burocracia estatal.

Este tipo de dispersión de individuos y funciones para la provisión estatal de educación se denomina "sistema educativo" y en su base todos los individuos de la población debieren estar incluidos y guardar relaciones de equivalencia respecto de los demás individuos. En esta pirámide cada parte está racionalizada de acuerdo a una función predefinida, fija y estática en el tiempo: una racionalidad gubernamental que pretende proveer mismos saberes y mismas experiencias educacionales a todos los niños sin más distinciones que las naturalizadas en los criterios de educabilidad; a saber, las diferencias de edad y ninguna otra.

13 Este principio de "simultaneidad sistémica" ya se encuentra en Comenius (1986). Véase Narodowski (2001). 
A medida que se desciende en la jerarquía piramidal, los agentes tienen menos poder de decisión ya que justamente ellos son los que deben actuar homogéneamente, sin hacer ni más ni menos que lo que se les demanda y sufriendo severas sanciones cuando se transgreden por acción u omisión las funciones pre asignadas: modificar funciones podría hacer tambalear la homogeneidad de la oferta y el mismo principio de igualdad sobre el que se basa este escenario. La auto reproducción de esta homogenización, es decir, la estabilidad de la pirámide, es la cuestión más significativa y el derecho a la educación sólo puede realizarse dentro de las reglas prescriptas (Senett, 2006); de otra manera, se estarían estableciendo especificidades que no se corresponde con la pretensión de igualdad.

En conclusión, el funcionamiento de la provisión de educación escolar en este escenario no puede obedecer sino a una lógica monopólica estatal ya que solamente el Estado, por medio de su propia burocracia, es el que está habilitado para ofrecer educación escolar. El monopolio estatal de la educación escolar coagula en un esquema único que subsume a todas las diferencias posibles entre infancias (de clase, raza, etnia, género, opción cultural etc.) para los habitantes de un mismo espacio territorial a fin de garantizar una provisión en la que a todos se les brinde lo mismo.

Para garantizar esta homogeneidad el Estado, por medio de su burocracia, establece un conjunto de saberes a ser adquiridos en cada momento del proceso de escolarización. Como, obviamente, no es posible enseñarlo todo (y como tampoco es conveniente puesto que hay saberes que no contribuyen al bien común o al ideario constitutivo de una sociedad democrática), es menester proceder a efectuar recortes de aquello que va a formar parte del bien homogéneo distribuido: la burocracia estatal debe definir criterios de selección de saberes que habrán de plasmarse en lo que se denominará curriculum: una suerte de dispositivo de articulación y jerarquización de contenidos.

Para garantizar en los saberes distribuidos a todos los habitantes escolarizados, el equilibrio propio de un Estado representante del interés general, los criterios utilizados no deben atender a ninguno de los intereses o las tradiciones particulares de los grupos que conforman la sociedad sino que deben mantener un principio de interés general en el que todos acuerden. Es decir, no pueden incluirse en el curriculum ni creencias singulares, ni tradiciones locales que confronten con otras ni conocimientos que puedan ser cuestionados. En este escenario, la única solución posible para estas tensiones es encontrar un régimen epistémico que se legitime por su neutralidad e imparcialidad; un régimen de verdad basado no en pautas particulares sino en la misma pretensión de objetividad. Ese régimen epistémico es, obviamente, la ciencia.

Las burocracias estatales disciernen los saberes a enseñarse en las escuelas comunes amparándose en su significatividad científica y colocando a la ciencia (a las ciencias físico matemáticas, las ciencias naturales y las ciencias sociales) como árbitro imparcial, como juez natural de la selección de conocimientos y de la vigilancia epistemológica respecto de su distribución. 
En este escenario, es imprescindible que esta función arbitral sea de la ciencia (y de los científicos) sea un supuesto inapelable desde la propia configuración de un sistema escolar bajo control monopólico estatal. Para que esto sea posible, tiene que estar claro el estatuto jurídico de la infancia como razón de Estado expresado en una implícita alianza entre la escuela y la familia por medio de la cual, cualquier conflicto que se pudiere presentar en virtud de las diferencias entre los conocimientos impartidos por la escuela y aquellos tenidos como verdaderos por la familia o cualquier forma comunitaria a la que pertenezca el niño escolarizado, el conflicto habrá de dirimirse, siempre, a favor de la escuela, la que por este medio termina cumpliendo un rol civilizatorio. La familia debe adaptarse a la escuela y no puede cuestionar el valor de verdad de los saberes que allí se distribuyen (Narodowski, 2001).

En otras palabras, la alianza escuela familia es, en este escenario, sobre todo un contrato de adhesión por parte de familias y comunidades a la lógica monopólica que asume la distribución de saberes, la cual construye en los hechos una analítica de la verdad que permite distinguir aquellos saberes que son verdaderos de los que son falsos, aquellos genuinos de los ilegítimos, aquellos beneficiosos de los perjudiciales, aquellos constructivos de los subversivos. Una analítica de la verdad que implica sistemas de control respecto de qué se sabe (y de que saberes, culturas o tradiciones deben ser censurados o reprobados) pero también de cómo se sabe: qué idiomas deben utilizarse, qué tipo de lengua, qué tecnologías de trasmisión de las palabras oral y escrita e, incluso, qué método para enseñarlo.

Respecto de este proceso de homogenización de los saberes por parte del Estado se suscitan tres problemas en este escenario. El primero, se circunscribe al cómo mantener actualizados los conocimientos a ser distribuidos escolarmente al mismo tiempo que avanzan las ciencias, sin producir fracturas relevantes en la pirámide de organización del sistema de escuelas. Para lograrlo, las burocracias estatales requieren de nexos sólidos con el mundo científico y una articulación inmediata con la base de la pirámide: el mundo escolar y la enseñanza efectiva de estos conocimientos. Para lograr esta articulación, la burocracia estatal controla todos los textos que serán leídos en las escuelas, aceptando los que se ajustan convenientemente a los avances científicos y desaprobando (y prohibiendo su utilización) a aquellos que no lo hacen. Al mismo tiempo cuenta con un cuerpo de inspectores de escuela que cuidan que esta cuestión, y muchas otras -como veremossean adecuadamente implementadas. Se trata de un proceso de evaluación de procesos operado en el momento de su realización.

El segundo problema es el relativo a los desacuerdos existentes en la propia comunidad científica respecto de una misma cuestión. La única opción posible para la burocracia estatal es tomar partido por alguna y prohibir las demás. Permitir que todas las posiciones científicas en pugna sean consideradas al mismo tiempo transgrede, claramente, el principio de igualdad dado que algunos aprenderán algunos saberes y otros no.

El tercer problemas es el relativo a la adecuación escolar de esos contenidos científicos; o sea, a la metamorfosis de un conocimiento científicamente desarrollado 
a un contenido escolar susceptible de ser aprendido por un individuo educable (Chevallard, 1985). Para mantener altos niveles de homogeneidad el proceso de transposición didáctica no debe quedar en manos de los docentes de cada escuela ya que los mismos podrían encontrar al problema soluciones diversas que habrían de corromper la homogeneidad o, incluso, soluciones ineficaces que alteraren el desiderátum de trasmisión equivalente en cuanto al estándar científico de los saberes. Es así que la burocracia estatal deberá estar lo suficientemente preparada desde el punto de vista de sus capacidades técnico-pedagógicas para elaborar diseños curriculares y metodologías didácticas capaces de ser adoptadas fácilmente por las escuelas, en su totalidad, en forma homogénea y sistemática. ${ }^{14}$

Sin embargo, y como ya pudo advertirse, la analítica de la verdad construida de hecho en la selección de saberes a ser distribuidos monopólicamente precisa de parámetros de legitimación que no se corresponden solamente con la ciencia positiva. Otros contenidos a enseñarse en las escuelas también deben ser adecuadamente controlados, en este escenario, por el Estado. La escuela no solamente enseña a los niños ciencia sino que además trasmite pautas de conducta que encierran valores morales vinculados a todos y cada uno de los aspectos de la vida social y que implicaría forzar el encuadre científico el incluirlos.

La moral y las valoraciones deben tener también un canon estatalmente aceptado. En algunos casos, el Estado concibe que la religiosa es la única forma posible de determinar valores morales en la medida que las Iglesias (especialmente en el cristianismo occidental) han mantenido el monopolio en la producción, distribución o mantenimiento de los universos sacralizados y trascendentes (Luckmann, 1996). En otros casos, el Estado es el que monopoliza la idea de bien y destierra de la educación común cualquier forma de expresión trascendente, resituando a las cuestiones religiosas en el contexto de su versión científica (en la historia de las religiones) o condenándola, directamente, al lugar de la superstición o la versión precientífica acerca de la realidad.

Si ocurre el primero de los casos, la burocracia estatal va a estar integrada directa o indirectamente por la jerarquía eclesiástica, la que va a disponer de la elaboración del saber homogeneizado en lo atinente a cuestiones morales entrando, en algunos casos, en una cierta competencia y en no pocos conflictos con los sectores de la burocracia estatal dedicados a la elaboración científica de conocimientos. Si ocurre el segundo de los casos, las burocracias estatales se ven, en este escenario, en la obligación no solamente de constituir una moral laica o al menos no religiosa sino que, además, se sitúan en el lugar del conflicto en contra de las religiones. Erigen así una tabla de valores epocales, situacionales pero avalados por el curriculum estatal y legitimados por su accionar.

14 Como hemos advertido hace ya mucho tiempo, la burocracia estatal que gobierna en este escenario los sistemas educativos precisan de "pedagogos de Estado" operando orgánicamente (Narodowski, 1998). 


\section{LOS PROBLEMAS DE LA PRETENSIÓN IGUALADORA}

Este escenario que hemos descripto tiene en la igualdad un vector central que conforma el desiderátum de lo social. Hemos explicado cuáles son las condiciones que debe reunir el Estado, cómo elaborar e implementar sus políticas educativas y cómo se habrá de conseguir una verdadera igualdad.

Sin embargo, las cosas no son tan fáciles. En el desarrollo de las características del escenario o de las políticas públicas necesarias para alcanzar la igualdad aparecen algunos problemas que limitan o contradicen la posibilidad de obtenerla. No se trata aquí de problemas externos sino de cuestiones inmanentes al mismo escenario que, de suceder, van en detrimento de la misma igualdad o de alguno de los principios propios de la democracia que constituyen los fundamentos del escenario.

Vamos, pues, a describir tres de esos problemas para así plantear las posibilidades y límites del escenario descripto.

\section{PRIMER PROBLEMA: ¿DE QUIÉN ES EL NIÑO?}

La educación común fortalece a la igualdad en asociación al tiempo en que ella es obligatoria, universal, y comprende a todos los individuos educables. Esto significa que la igualdad de oportunidades educativas se fortalece como principio cuántos más años de escolaridad común existan, cuantos más días de clase tenga cada uno de esos años y cuantas más horas del día abarque cada uno de esos días de clase. Es cierto que si la oferta escolar es heterogénea, una escuela con menor valor en la distribución de saberes que otras difícilmente compense sus problemas con más tiempo. Pero, a la recíproca, en un sistema escolar que trasmita los valores y habilidades adecuados a todos, el terreno de juego tendrá más chances de igualar las desigualdades socioeconómicas de origen, cuanto más tiempo abarque la escolaridad.

El tiempo, por lo tanto, no es una variable por la que alguien pueda voluntariamente optar. Su criticidad amerita la obligatoriedad no solamente de la educación primaria o básica (y eventualmente de la secundaria) sino, hacia atrás, la escolaridad en los primeros años de la vida del niño, los que habrán de compensar las desigualdades de origen en la crianza de los niños.

Así, el jardín de infantes, la educación preescolar, la educación maternal o las guarderías (diferentes nombres para designar la educación desde el nacimiento hasta el inicio de la educación primaria) pasan en este escenario a formar parte del derecho a la educación por su carácter igualador y por ende, tendrán las mismas características que la educación fundamental: financiada por el estado, homogénea en su oferta, regulada por la burocracia estatal etc. A la vez, esta oferta permite que las madres adolescentes o jóvenes puedan ejercer su propio derecho a la educación escolar mientras sus hijos pequeños concurren a la escuela (Mayer, 1997).

Esta situación conlleva algunas cuestiones que es menester analizar y que si bien se plantean para el adelantamiento de la obligatoriedad escolar terminan siendo válidos para toda la escolarización de la infancia. La primera es la extensión del principio de infancia como razón de Estado para llevarlo a los primeros años de 
la vida de cada individuo. Los derechos parentales sobre los hijos (la denominada patria potestad) sufren con esta nueva situación un recorte mayor en la medida que las decisiones sobre los hijos estarán supeditadas a la necesidad de más años de provisión educacional del estado por medio de su burocracia.

Las decisiones familiares de los padres respecto de la educación de sus hijos quedan ahora dominadas por las decisiones de la burocracia estatal respecto de la escolarización (una alianza escuela familia en la que, como se vio, la desavenencia cultural se dirime a favor de la escuela) y a favor, en consecuencia, del mejoramiento de las oportunidades educacionales de los niños más pequeños. Las prácticas de crianza, tradicionalmente asociadas a la acción familiar y especialmente a la maternidad, se desplazan a favor de su incorporación a la pirámide del monopolio estatal. Esto conlleva, pues, una pregunta ineludible de las políticas públicas sobre la infancia: ¿cuál es el límite inferior en la escolarización obligatoria de los niños? ¿Y cuáles son (si es que existen) los derechos paternos por encima de la acción estatal (Ackerman, 1981)?

Esta primer pregunta, en nuestro escenario, la responde la burocracia estatal en base a los aportes de la ciencia y al sentido común de la aceptación a su legitimidad práctica.

El problema es que la cuestión pone en evidencia la característica compulsiva del dispositivo de alianza: un modelo de educación basado en la igualdad tiende a priorizar la acción estatal (común, homogénea) por sobre la acción parental (diversa, heterogénea) y en más de un sentido plantea la cuestión del paternalismo estatal, el Estado ocupando el rol tradicional de los padres. Extremando el razonamiento se llega a posturas típicas de dictaduras totalitarias en las que el niño no es de los padres sino del Estado. Por eso, el delgado equilibrio entre el respeto a la potestad familiar sobre el niño y la pretensión de igualdad constituye una de las grietas del escenario anteriormente descripto.

\section{SEGUNDO PROBLEMA: ¿SON POSIBLES ESCUELAS HETEROGÉNEAS?}

La composición social de la matrícula en cada escuela de educación fundamental está determinada por el lugar en el que la escuela está situada tomando como supuesto que, al menos en este nivel de enseñanza, la proximidad de la escuela al hogar es un valor relevante y que el transporte genera costos explícitos y ocultos.

En nuestro escenario, una sociedad dividida en clases sociales, puede existir un considerable nivel de integración demográfica entre las diferentes clases sociales toda vez que el Estado se ha encargado de las otras áreas del desarrollo social (y en los grandes conglomerados, del desarrollo urbano) de la misma manera que lo ha hecho con la educación escolar: la salud, la seguridad pública, la higiene urbana, el mantenimiento urbano -los denominados servicios públicos- están igualmente controlados monopólicamente por el Estado y este garantiza la rigurosa igualdad en la distribución de todos esos recursos de acuerdo a las necesidades concretas de la población. 
La consecuencia obvia de esta situación es que en las grandes ciudades, por ejemplo, para que la oferta escolar sea igualitaria no habrán de existir diferencias significativas en el precio de la propiedad inmueble determinadas por la zona en la que dicha propiedad está ubicada. Más aún, así como el Estado obliga a una escolarización monopólica debería para, evitar procesos de autosegregación social, debe también prohibir taxativamente que los sectores de mayores recursos económicos accedan a financiar voluntariamente ninguno de los servicios públicos financiados y regulados monopólicamente por el Estado como modo de quebrar cualquier intento de segregar o autosegregarse.

En consecuencia, los centros urbanos, en nuestro escenario, habrán de mostrar una concentración social más bien heterogénea que va a ser replicada en cada salón de clases de cada escuela.

El problema es que varias de las acciones que debe encarar el Estado para lograr heterogeneidad de sectores sociales en los diversos espacios urbanos para así conseguir escuelas comunes heterogéneas, se contradicen con algunos de los principios básicos de nuestro escenario tanto en lo político/institucional como en lo económico.

Por ejemplo, el Estado debería regular el mercado inmobiliario y, como mínimo, imponer precios máximos al valor de la propiedad inmueble a fin de que la localización de las viviendas no conforme procesos de segregación social basado en el poder adquisitivo. En otro sentido, el Estado tampoco podría permitir la conformación de sectores urbanos signados por características étnicas, religiosas o raciales pues la consecuencia educacional es que la proximidad de la escuela común suponga una demanda guetificada que va en contra de la igualdad.

Como puede verse, la igualdad necesita, en este sentido, el monopolio estatal tanto en la educación como en áreas más generales de la vida social lo que trae consecuencias críticas en relación a algunos principios básicos que sostienen el escenario.

\section{TERCER PROBLEMA: ¿ES POSIBLE LA SINGULARIDAD?}

En este escenario que estamos analizando, algunos sectores de la población puede que reclamen para sí una cierta singularidad cultural: esperan educar a sus hijos en unos contendidos que no son tenidos en cuenta por el Estado o por la burocracia estatal y a menudo -tampoco- por la mayoría de la población. Vamos a suponer, a fin de evitar controversias especiales, que no se trata de expresiones contrarias a los postulados constitutivos de la democracia de nuestro escenario: simplemente, no son compartidos por quienes planifican el sistema educativo y no son tenidos en cuenta en el procedo de homogenización del saber por alguno de los motivos vinculados al proceso de selección de contenidos escolares ya enumerados en párrafos anteriores.

Esta singularidad suele ser, frecuentemente, de carácter religiosa no solamente por el rol central que lo trascendente juega en la vida cotidiana de los individuos de esta sociedad (aún cuando el Estado haya desterrado lo religioso de 
los escolar) sino también por el hecho constitutivo de este escenario consistente en que tradicionalmente la educación hubo de estar en manos de corporaciones religiosas para ser luego cooptadas por el Estado; lo que convierte a este reclamo en el reconocimiento de una suerte de herencia que conserva su peso a pesar de los años.

Pero el reclamo por la existencia escolar de una singularidad además de religiosa, puede ser cultural -es decir, el acento en determinadas opciones culturales-, étnica, de género, linguística etc. $\mathrm{O}$ simplemente atada a ciertos procedimientos, conductas, estilos de vida etc.

El planteo en pro del reconocimiento de lo singular trae consigo varias cuestiones que también se convierten en dilemáticas en nuestro escenario. Si el Estado rechazase de plano esta pretensión dejaría de ser un Estado democrático y la educación común implicaría forzar las convicciones de algunos grupos sociales: la igualdad educacional sería establecida solamente para aprender los saberes estipulados por la burocracia estatal y el derecho a la educación se convertiría, por ende, en el paradojal derecho a ser indoctrinado.

Ahora bien, si el Estado aceptare la posibilidad de expresión de algunas de estas pretensiones (por ejemplo, los que ideológica o axiológicamente más se acercan a su ideal escolar) y no de otras (más lejanas a su ideario), estaría relegando a algunos grupos. Pero si el Estado aceptara en un todo a cada una de ellas, desparecería la idea misma de lo "común" -la homogeneidad de la oferta escolar- de la escuela común y el sistema educativo se convertiría en una suerte de oferta heterogénea y a la carta.

Por ejemplo, la burocracia del nivel descentralizado o los propios docentes ¿pueden conseguir garantizar el ejercicio de esta singularidad a condición de que no se convierta en la base epistémica o valorativa de un curriculum de valor inferior al del resto de las unidades o que sea un pretexto para proceder a implementar formas de segregación o autosegregación?

Esta tensión genera un problema más ya que aun considerando enteramente aceptable en una sociedad democrática este requerimiento por lo singular (aún con todos los problemas de gestión concreta que generaría) el mismo no puede ser una excusa para la segregación y especialmente para la autosegregación y la consecuente desaparición de la escuela común, no merced a la desaparición del saber homogéneo sino merced a ofertas socialmente diferencias desde los social. En otras palabras en este escenario de igualdad como prioridad, el recurso a la singularidad no podría ser una excusa para la segregación social en cualquiera de sus modalidades.

Las respuestas posibles al requerimiento de singularidades que pretenden para sí un tratamiento como si fueran un universal dentro de los límites de nuestro escenario se muestran limitadas a dos opciones: o el Estado acepta la existencia de un núcleo de saberes heterogéneos en la escuela común, garantizando la sobrevivencia de esta por un peso importante de un núcleo de saberes que se conservan como homogéneos "un zócalo común" o el Estado no acepta la introducción de ninguna forma de flexibilización de su oferta.

En el caso de la segunda opción, el mantenimiento a rajatabla de la homogeneidad escolar como la única opción implica la directa prohibición de las 
formas específicas de saberes que atiendan a lo que se considera singularidades. Esta prohibición implicaría, por ejemplo, desde la interdicción a la práctica religiosa devocional cotidiana hasta el habla en lengua aborigen.

Una visión complementaria a la segunda opción sería posible que cada uno de esos grupos reciba los contenidos homogéneos en las escuelas comunes, pero también los específicos aunque en forma complementaria, después de concluida la jornada escolar o el año escolar y para evitar que sólo los sectores de mayores recursos financieros hagan uso de este derecho, el Estado financiaría cada uno de estos emprendimientos dejando en manos de estos grupos los contenidos y la metodología a adoptar en este segmento de la escolarización. Obviamente, le quedaría al Estado una relevante función de inspección que asegure que los contenidos y metodologías específicas no son abiertamente contrarios a los contenidos y las metodologías de las escuelas (Ackerman, 2001).

La negativa a admitir variantes a la homogeneidad curricular y la consolidación de un monopolio estatal en la provisión de educación escolar solo es posible pues en sociedades democráticas que posean alguna de estas dos características. La primera es ser una sociedad con un Estado fuerte y muy legitimados socialmente, especialmente en el ejercicio de la violencia que garantice la imposibilidad de cuestionamientos a la oferta estatal. Los sectores sociales que reclaman por su singularidad se saben políticamente débiles frente a la iniciativa estatal y son conscientes que cualquier forma de cuestionamiento puede generar sanciones de diverso tipo. Si esta debilidad es mayoritaria, ya no estaríamos en presencia de una democracia política. La segunda característica posible es la de ser una sociedad cerrada, con un alto consenso social respecto de decisiones que reflejan una sociedad sin grandes disparidades religiosas o culturales. La gran mayoría de los ciudadanos y su estructura de representación política -partidos políticos, sindicatos, asociaciones de ciudadanos- mantienen una relevante cohesión en base a acuerdos básicos muy fuertemente anudados.

En el caso de la primera opción, flexibilidad estatal frente a la imposición de saber homogéneo, las posibilidades, en este escenario, no son muchas. Una consistiría en que cada grupo tenga tiempo de escuela habilitado por el Estado en las que pueda practicarse lo atinente a su singularidad pero no sería más que una solución parcial que profundiza una ya dada fuera del tiempo escolar.

La solución de fondo consistiría en que cada uno de esos grupos pueda regentear su propia escuela común (un tipo de establecimiento al que a partir de ahora denominaremos "escuela privada") en la que se asegurará la enseñanza de los contenidos y la metodología de la escuela común tradicional (a la que a partir de ahora denominaremos escuela oficial) y se agregarán los contenidos y metodologías específicas requeridas por cada grupo. En el extremo en que el Estado claudique su capacidad de provisión escolar, todas las escuelas serían "privadas". Al igual que en la propuesta anterior, el Estado se guarda la función de inspeccionar la consistencia de contenidos y metodologías. 
Respecto del financiamiento, en este caso la situación es más compleja puesto que por motivos de ecuanimidad el Estado deberá financiar a cada uno de estos grupos: si el principio de homogeneidad se pone en cuestión con escuelas que respetan singularidades diversas, la vulneración del principio de gratuidad -escuelas que dejen de ser gratuitas- implicaría necesariamente la admisión de la imposibilidad de alcanzar la igualdad.

Sin embargo, es difícil de justificar cómo esta disposición de respeto por las singularidades puede mantener incólume el principio de Igualdad. La única posibilidad consistiría en suponer que el saber trasmitido por cada escuela es diferente pero epistémicamente equivalente y los valores procesados también diferentes pero axiológicamente equivalentes. El Estado ya no tendría el monopolio de la educación escolar y sus funciones quedarían reducidas al financiamiento y a la inspección y al arbitraje. Pero esto sería, claro, otro escenario.

\section{CONCLUSIONES: LOS DESAFÍOS DE LA IGUALDAD}

El escenario aquí descripto podría resumirse en los siguientes conceptos nucleares: monopolio estatal sobre la educación escolar en una sociedad democrática, escolaridad gratuita, obligatoria y común la mayor cantidad de tiempo posible; infancia como razón de Estado, alianza escuela familia con primacía de lo escolar; la ciencia como paradigma del conocimiento que debe ser procesado. Todo esto apunta a la intransigencia en el respeto al principio de igualdad en el contexto del máximo derecho a la educación.

Pero para que este escenario sea posible hay al menos tres cuestiones que deben ser sacrificadas sino fuertemente limitadas. Primero, la potestad paterna, la que quedará en una posición subalterna respecto de las necesidades planteadas por la burocracia estatal. Segundo, un desarrollo urbano determinado por el mercado el que quedará a merced de las regulaciones estatales que impidan procesos de segregación o autosegregación que a su vez conformen escuelas con demanda homogénea. Tercero, el derecho a educar y a educarse de acuerdo a pautas culturales singulares, que quedará sujeto al modelo epistémico o axiológico que la burocracia estatal determine como válido para "lo común" en una sociedad determinada. ${ }^{15}$

Estas tres cuestiones permiten aproximar una explicación a los motivos por los cuales el escenario social descripto tiene enormes problemas para realizarse en sociedades concretas, a la sazón en una sociedad capitalista democrática y diversa en la que el accionar Estado y de sus burocracias plantea significativos problemas de legitimación (Bell, 1976; Habermas, 1981). En otras palabras, el escenario descripto solamente sería asimilable a sociedades en las que el Estado tiene una enorme capacidad de legitimación de su práctica (por la vía que fuere, dentro de

15 Como puede inferirse, el problema aquí planteado transita otro capítulo de la controversia filosófica respecto de la tensión entre libertad y acción estatal. Véase Sen (1995). 
unos lábiles límites democráticos) y, a la vez, no existen singularidades reclamando su propia identidad educacional.

¿Estas objeciones impiden, por tanto, construir un sistema educativo igualitario? ¿La igualdad ya no es un desiderátum concretable en una sociedad capitalista, democrática y diversa?

Lo que, entendemos, nuestro análisis ha demostrado es que el principio de igualdad resulta poco menos que impracticable en las condiciones que presenta el escenario, sea porque su aplicación contradice principios básicos que constituyen una democracia, sea porque la hace fácticamente imposible. Lo que estamos sugiriendo es que las políticas públicas para la escolarización de la infancia deben operar en el supuesto de otros escenarios que hagan posible la igualdad.

Este elemento es no menor. La mayoría de los sistemas escolares del mundo, especialmente los latinoamericanos, operan en escenarios reales en los que las condiciones institucionales de la democracia presentan una debilidad que marca una diferencia enorme con el escenario aquí henos desarrollado y, como si esto no fuera de por sí suficiente, las condiciones sociales de segregación y desigualdad son, en muchos casos, absolutamente contrarias respecto de las requeridas. La consecuencia de lo anterior es dura: si en un escenario como el reseñado en este artículo resulta muy complicado implementar políticas públicas para la igualdad, mucho más lo será en algunos de los escenarios sociales y políticos actuales.

Lo que queda claro, en consecuencia, es que forzar la implementación de políticas públicas en los escenarios reales atravesado por la pobreza y la diversidad, con un Estado con bajo nivel de legitimación, como si estos fueran análogos al que aquí describimos solamente lleva al fracaso y a la desilusión siendo que lo que ha fallado no es el principio mismo de igualdad sino el diagnóstico de la realidad social -la identificación de las características del escenario-y, por ende, la estrategia de políticas públicas para intervenir en él.

\section{REFERENCIAS}

Acrerman, Bruce. Social justice in the liberal sate. New Haven: Yale University Press, 1981.

Ackerman, David. Prayer and religion in the public schools. New York: Novinka Books, 2001.

Archer, Margaret. Social Origins of Educational Sytems. London: Sage, 1979.

BeLl, Daniel. The cultural contradictions of capitalism. New York: Pantheon Books, 1976.

Chevallard, Yves. La transposition didactique. Grénoble: La Pensée Sauvage, 1985.

Comenius, Jan A. Didactica magna. Tradução Saturnino Lopez Peces. Madrid: Akal, 1986.

Dewey, John. Democracy and education. An introduction to the philosophy of education. Toledo: Students Handouts, 2008. 
Eisenmann, Louis. Teacher professionalism: a new analytical tool for the history of teachers. Harvard Educational Review, Cambridge: Harvard Education Publishing Group, v. 61, n. 2, p. 215-225, 1991.

Glenn, Carl. The myth of common school. Amherts: University of Massachussets Press, 1988.

Habermas, Jürgen. Jürgen Habermas (1 Problems of legitimation in late capitalism). London: Penguin Books, 1981.

Hincapié, Adrián; Barriga Dávalos, Pedro. John Roemer: trayectoria intelectual, marxismo analítico y justicia distributiva. Escenario XXI, v. 1, n. 8, p. 29-54, 2011.

Levin, Henry. The economics of educational choice. Economics of Education Revierw, Atlanta: Elsevier, v. 10, n. 2, p. 137-158, 1991.

Locke, John. John Locke on education. New York: Teachers College Record, 1971.

Luckmann, Thomas. The privatization of religión and morality. In: Heelas, Peter; Phelps, Morris. Detraditionalization. Critical reflections on authority and identity. Cambridge: Blakwell, 1996. p. 203-266.

Martinez Boom, Alberto. La escuela pública. Del socorro a los pobres a la policía de los niños. In: Zuluaga, Olga. Foucault, la pedagogía, la educación. Pensar de otro modo. Bogotá: Cooperativa del Magisterio, 2005. p. 17-36.

. Dejad que los niños vengan a mi. Educación y Pedagogía, Medellín: Universidad de Antioquia, v. 23 n. 60, p. 31-50, 2011.

.; Castro, Jorge. Crónicas del desarraigo. Bogotá: Cooperativa del Magisterio, 1991.

Mayer, Susan E. What money can't buy. Family income and children's life chances. Cambridge: Harvard University Press, 1997.

Miller, David. Principles of social justice. Cambridge: Harvard University Press, 2000. Narodowski, Mariano. Para volver al Estado. Del pedagogo de Estado al pedagogo de la dversidad. Propuesta Educativa, Buenos Aires: FLACSO, n. 17, p. 45-65, 1998.

. Infancia e poder. Conformação da pedagogia moderna. São Paulo: Universidade São Francisco, 2001.

. No es fácil ser adulto. Asimetrías y equivalencias en las nuevas infancas y adolescencias. Educación y Pedagogía, Medellín: Universidad de Antioquia, v. 23, n. 60, p. 17-29, 2011.

.; Brailovsky, Daniel. La cuestión del fin de la Razón de Estado en la historia de la escolarización. Cadernos de História da Educação, Uberlândia, EDUFU, n. 4, p. 95-116, 2005.

Rawls, John. Teoría de la justicia. México: Fondo de Cultura Económica, 1993.

SEn, Amartya. Inequality reexamined. Cambridge: Harvard Univerity Press, 1995.

Senett, Richard. The new culture of capitalism. New Haven: Yale University Press, 2006. 
TYack, David. Ways of seeing: an essay on the history of compulsory schooling. Harvard Educational Review, Cambridge: Harvard Education Publishing Group, v. 46, n. 3, p. 355-389, 1976.

Seeking common ground: public schools in diverse society. Cambridge: Harvard University Press, 2003.

Wilkins, Bernard. Should public education be a federal fundamental right? Education E Law, Brigham Young University, n. 5, p. 261-276, 2005.

Zelizer, Vivian. Pricing the priceless child: the changing social value of children. New Jersey: Princeton University Press, 1994.

\section{SOBRE EL AUTOR}

Mariano Narodowski es doctor en educación por la Universidade Estadual de Campinas (UNICAMP). Profesor de la Universidad Torcuato Di Tella.

E-mail:mnarodowski@utdt.edu

Recebido em agosto de 2012

Aprovado em outubro de 2012 


\section{MARIANO NARODOWSKI}

\section{Políticas públicas e infancia: deseos y límites a la igualdad en la educación}

$\mathrm{El}$ artículo describe un escenario social a partir de los conceptos de monopolio estatal sobre la educación escolar en una sociedad democrática, escolaridad gratuita y obligatoria la mayor cantidad de tiempo posible; infancia como razón de Estado, alianza escuela familia con énfasis en lo escolar y ciencia como paradigma del conocimiento enseñable. Los elementos apuntan hacia políticas públicas para la educación fundamental que respetan el principio de igualdad en el marco del máximo derecho a la educación. Para que este escenario sea posible, se delimitarán algunas cuestiones: la potestad paterna sobre la infancia, un desarrollo urbano mercantilizado y el derecho absoluto a educar y a educarse según pautas culturales singulares. El artículo indaga sobre los motivos de estas limitaciones y sobre las posibilidades de la política pública de sostener el irrestricto respeto al principio de igualdad modificando algunos de los elementos del escenario social originariamente propuesto.

Palabras clave: igualdad; monopolio estatal; políticas públicas; derecho a la educación.

\section{Public policies and childhood: wishes and limits for equality in education}

This article describes a social scenario using the concepts of state monopoly on education in a democratic society, free and compulsory education for as long as possible; childhood as a Reason of State, the alliance between schools and families with emphasis on the student and science as a paradigm of what can be taught. The elements point to public policies on primary education which respect the principle of equality from the perspective of the full right to education. For this scenario to be possible, some issues will be delineated: parental authority over childhood, commoditized urban development and absolute right to educate and be educated according to unique cultural agendas. The article inquires about the reasons for these limitations and the possibilities of public policies ensuring unrestricted respect for the principle of equality, modifying some of the elements of the social scenario originally proposed.

Keywords: equality; state monopoly; public policies; right to education. 


\section{Políticas públicas e infância: desejos e limites para a igualdade na educação}

$O$ artigo descreve um cenário social com base nos conceitos de monopólio estatal sobre a educação escolar em uma sociedade democrática, escolaridade gratuita e obrigatória durante o maior tempo possivel; infância como razão de Estado, aliança entre escola e família com ênfase no escolar e ciência como paradigma do que se pode ensinar. Os elementos apontam para políticas públicas para a educação fundamental que respeitamo princípio de igualdade na perspectiva do direito máximo à educação. Para que esse cenário seja possivel, algumas questôes serão delimitadas: o poder paterno sobre a infância, um desenvolvimento urbano mercantilizado e o direito absoluto a educar e ser educado de acordo com pautas culturais singulares. O artigo indaga sobre os motivos dessas limitaçôes e sobre as possibilidades de a política pública manter o respeito irrestrito ao princípio de igualdade, modificando alguns dos elementos do cenário social proposto originariamente. Palavras-chave: igualdade; monopólio estatal; politicas públicas; direito à educação. 